medRxiv preprint doi: https://doi.org/10.1101/2020.12.09.20246850; this version posted December 11, 2020. The copyright holder for this preprint (which was not certified by peer review) is the author/funder, who has granted medRxiv a license to display the preprint in perpetuity.

It is made available under a CC-BY 4.0 International license .

\title{
Pre-stimulus low-alpha frontal networks characterize pareidolias in Parkinson's disease
}

\author{
Gajanan S. Revankar ${ }^{1}$, Yuta Kajiyama ${ }^{1}$, Noriaki Hattori ${ }^{1,2}$, Tetsuya Shimokawa ${ }^{3}$, Tomohito Nakano ${ }^{1}$, \\ Masahito Mihara ${ }^{1,4}$, Etsuro Mori $^{5}$ and Hideki Mochizuki ${ }^{1 *}$ \\ ${ }^{1}$ Department of Neurology, Graduate School of Medicine, Osaka University, Osaka, Japan \\ ${ }^{2}$ Department of Rehabilitation, Faculty of Medicine, Academic Assembly, University of Toyama, Toyama, \\ Japan
}

${ }^{3}$ Center for Information and Neural Networks (CiNet), National Institute of Information and Communications Technology (NICT), Osaka, Japan

${ }^{4}$ Department of Neurology, Kawasaki Medical College, Okayama, Japan

${ }^{5}$ Department of Behavioral Neurology and Neuropsychiatry, Osaka University, Osaka, Japan

\section{*Correspondence:}

Hideki Mochizuki

Department of Neurology, Graduate School of Medicine, Osaka University

2-2, Yamadaoka, Suita, Osaka, Japan - 5650871

Phone : +81-6-6879-3571

hmochizuki@neurol.med.osaka-u.ac.jp

Manuscript details: Abstract count - 245 words, Main-text count -3570 words, Figures -2 , Tables -3 .

Running title: Graph theory for pareidolias.

Keywords: Parkinson's disease, pareidolia, EEG, graph theory, hallucinations, frontal cortex.

Conflict of Interest Statement: Nothing to report.

Authors' Roles: Conceptualization - G.S.R., Y.K., T.S., N.H., E.M. and H.M.; Methodology - G.S.R., T.N. and Y.K.; Software, Validation - G.S.R., Y.K. and T.S.; Formal analysis, Data curation - G.S.R. and Y.K.; Writing - original draft preparation - G.S.R.; Writing - review \& editing - Y.K., T.S., T.N., N.H., M.M., E.M and H.M.; Supervision, Funding acquisition - G.S.R. and H.M. 
medRxiv preprint doi: https://doi.org/10.1101/2020.12.09.20246850; this version posted December 11, 2020. The copyright holder for this preprint (which was not certified by peer review) is the author/funder, who has granted medRxiv a license to display the preprint in perpetuity.

It is made available under a CC-BY 4.0 International license.

\section{Abstract}

Background: Parkinson's disease (PD) patients susceptible to visual hallucinations experience perceptual deficits in the form of pareidolias. While pareidolias necessitate top-down modulation of visual processing, the cortical dynamics of internally generated perceptual priors on pareidolic misperceptions is unknown.

Objectives: To study pre-stimulus related EEG spectral and network abnormalities in PD patients experiencing pareidolias.

Methods: 21 PD in-patients and 10 age-matched healthy controls were evaluated. Neuropsychological assessments included tests for cognition, attention and executive functions. To evoke and quantify pareidolias, participants performed the noise pareidolia test (NPT) with simultaneous EEG recording. PD patients were subdivided into two groups - those with high pareidolia counts $(\mathrm{N}=10)$ and those without $(\mathrm{N}=11)$. EEG was analyzed $1000 \mathrm{~ms}$ before stimulus presentation in the spectral domain (theta, low-alpha and high-alpha frequencies) with corresponding graph networks that evaluated small-world properties, efficiency and centrality measures. Statistical analysis included ANCOVA and multiple regression to evaluate the differences.

Results: PD group with high pareidolias were older with lower scores on neuropsychological tests. Their prestimulus EEG low-alpha band showed a tendency towards higher frontal activity $(\mathrm{p}=0.06)$. Graph networks showed increased normalized clustering coefficient $(\mathrm{p}=0.05)$, higher local parietal cortex efficiency $(\mathrm{p}=0.049)$ and lower frontal degree centrality $(\mathrm{p}=0.005)$. These network indices correlated positively to patients' pareidolia scores.

Conclusion: Pareidolias in PD are a consequence of an abnormal top-down modulation of visual processing which are defined by their frontal low-alpha spectral and network alterations in the pre-stimulus phase due to a dissonance between patients' internally generated mental-processing with external stimuli. 
medRxiv preprint doi: https://doi.org/10.1101/2020.12.09.20246850; this version posted December 11, 2020. The copyright holder for this preprint (which was not certified by peer review) is the author/funder, who has granted medRxiv a license to display the preprint in perpetuity.

\section{Introduction}

It is made available under a CC-BY 4.0 International license.

Parkinson's disease (PD) is predominantly a motor neurodegenerative disease, but those affected frequently show non-motor symptoms of psychosis such as mood disorders, impulsivity and hallucinations(1). Specifically, visual hallucinations (VH) have a strong prevalence in PD and contribute adversely to motor symptoms(2,3). Notably, $\mathrm{VH}$ are often preceded by minor hallucinations(4) wherein patients develop misperceptions of inanimate forms, objects or shapes(1). These visuo-perceptual deficits commonly occur in the form of 'pareidolias' and serve as precursors in identifying hallucinatory tendencies in PD patients(5). Several studies have previously shown a commonality of features between pareidolia and $\mathrm{VH}$ in patient populations(5-8) making it ideal to quantify pareidolias as a proxy for $\mathrm{VH}$.

Clinically, pareidolias can be quantified using the noise pareidolia test (NPT), a neuropsychological test wherein ambiguous patterns are presented to evoke illusionary responses in PD or dementia with Lewy body patients $(5,9)$. Pareidolias evoked on the NPT inherently prompt a visuo-perceptual demand(5) that requires reorienting attention depending on the salience revealed by the target. Recently, in a multimodal electroencephalography (EEG) experiment, we showed that PD patients exhibited abnormal top-down modulation of visual information 'during' pareidolic manifestations(10), suggestive of deficits in matching external sensory information with prior knowledge(11). However, considering the impact of abnormal priors in the causation of pareidolias(12,13), it is yet to be determined how neural information 'preceding' stimulus onset influences perception in those susceptible to pareidolias. To that end, we investigated how pre-stimulus cortical activity affects visual processing in PD patients during the performance of the NPT.

Prior studies on pre-stimulus oscillations have detailed the causal role of alpha frequencies in shaping and detecting sub-threshold stimuli(14). The voluntary visual attentional stream, defined by the connections between the frontal and parietal cortices, reportedly have a strong impact of alpha band oscillations in discriminating ambiguous targets(15) as well as prediction of perceptual decisions(16). Within the domains of attention and working memory, cortical alpha has been variously described under different terminologies such as mindwandering(17), creative ideation(18) or mental imagery(19), all to emphasize the influence of subjects' internallygenerated mental operations(20) in the absence of bottom-up sensory information. Considering that the communication between these exo- and endogenous attentional systems is impaired in PD patients with VH(21), low-frequency cortical oscillations may have a crucial role in the generation and maintenance of misperceptual tendencies. Specifically in PD without dementia, an increase in theta and low-alpha power is reported in restingstate recordings(22,23), with stimulus dependent studies reinforcing the importance of alpha bands(24). As symptoms and severity worsen, theta-pre-alpha rhythms in the frontal cortex has been shown to predict the cognitive decline(25) and is associated with hallucinations and/or delusions(26). Regardless, the visuo-perceptual dynamics in PD patients prior to stimulus onset is currently unknown. 
It is made available under a CC-BY 4.0 International license .

Whereas EEG studies conventionally use event-related and/or time-frequency analysis to study stimulus related effects, application of graph theory concepts to EEG data provides an efficient modality to examine alterations in higher-level whole-network brain areas(27). Given that pareidolias directly relate to a failure of attentional(10) and perceptual decision-making(6), the involvement of multiple attentional network domains(28) suggestive of a global cortical dysfunction cannot be overlooked. Therefore, evaluating pre-stimulus graph network metrics is speculated to clarify the abnormal network organization in such patients. Prior studies on PD have demonstrated decreased 'small world' properties, network efficiency and centrality measures when compared to healthy controls, with the outcomes worsening further in PD with dementias(29-31). Accordingly, in our present study, we will focus on deriving frequency specific graph metrics associated with pareidolias and their impact on visuoperception.

In summary, we hypothesized that PD patients with pareidolic tendencies demonstrate aberrant low-frequency oscillations with reciprocal network insufficiencies, addressed in an experimental paradigm where decisions are critically dependent on the individual's prior expectation of the stimulus. To achieve these aims, we performed an exploratory analysis on pre-stimulus intervals in PD patients and healthy controls (HC) to study the global and local (fronto-parietal) network dynamics using EEG spectral and graph-theory indices when participants performed the NPT. The results of our current work are expected to reinforce the findings of our prior study(10) and further our understanding on the effects of pre-stimulus cortical activity that shape post-stimulus pareidolic misperceptions. 


\section{Materials and Methods}

It is made available under a CC-BY 4.0 International license .

\section{General information and recording procedures}

We analyzed a dataset of 21 PD in-patients [age 70.4y \pm 8.5 (Mean, SD)] and age-matched 12 healthy controls $(69.4 \mathrm{y} \pm 8.5)$ whose details are published previously(10). Notably, PD patients with dementia were excluded (MMSE scores <24) and testing was done during 'ON' state of PD medication. All participants had normal or corrected-to-normal vision. Neuropsychological assessments relevant to the study were conducted by a trained psychologist, independent of experimenters who performed EEG. These included the Japanese adult reading test (JART), frontal assessment battery (FAB), Montreal cognitive assessment (MoCA) and the short-form of Benton's judgment of line orientation test (JLO, Form H). At the outset, we classified the patients based on the clinical noise pareidolia test (NPT), a standardized paper-based test to evoke and quantify pareidolias(32). The test comprises of black and white patches of visual noise with certain images containing faces. Correct responses refer to appropriate discrimination of faces from noise. However, when faces are identified in stimuli without a face, such responses are marked as pareidolias. Unidentified faces are categorized as missed responses. The test uses misperceptual cutoff scores of $0-1$ as non-pareidolics and $\geq 2$ as pareidolics. Of the 21 PD patients, 10 exhibited high pareidolia scores, henceforth classified as PD pareidolia type (PDP), and the rest were classified as PD non-pareidolic type (PDnP). There were 2 dropouts within the $\mathrm{HC}$ group (due to technical difficulties) bringing the total number of tested participants to $\mathrm{HC}=10, \mathrm{PDnP}=11$ and $\mathrm{PDP}=10$ for final EEG analysis. A summary of the participant details is shown in Table-1. Informed consent was obtained from all subjects and in accordance with the ethical standards of the Declaration of Helsinki, the institutional review board cleared the protocol for the study (approval number 18136).

For the EEG experiment, participants were shown 80 NPT images on a computer monitor, 60 with visual noise and 20 with faces embedded in them (Supplementary Fig. 1). The faces on the NPT are low-information, 2-toned images which requires configural knowledge based facial-feature processing(33). Cutoffs were appropriately increased. Participants were seated upright at a distance of $80 \mathrm{cms}$ from the monitor display which had images subtending a size of 700x700 pixels (width $\mathrm{x}$ height). Participants verbally responded to each image within 30s of stimulus presentation and the experimenter recorded the responses since patients' tremor severity may have prevented reliable manual responses. EEG data were recorded on a 32-channel Biosemi, ActiveTwo system at $2 \mathrm{kHz}$ sampling rate on ActiView software (LabVIEW). EEG recordings were re-referenced to average of all the electrode channels, pass filtered between $1 \mathrm{~Hz}$ and $45 \mathrm{~Hz}$ and down-sampled to $500 \mathrm{~Hz}$ for independent component analysis. Final EEG data was then reconstructed after independent components responsible for heartbeat, eyeblinks, and muscle related artifacts were removed using visual inspection. 
medRxiv preprint doi: https://doi.org/10.1101/2020.12.09.20246850; this version posted December 11, 2020. The copyright holder for this preprint (which was not certified by peer review) is the author/funder, who has granted medRxiv a license to display the preprint in perpetuity.

\section{Analysis of inter-stimulus intervals}

It is made available under a CC-BY 4.0 International license .

An overview of the evaluation procedure and analysis is shown in Fig.1.

Figure 1 - Overview of presentation, recording and analysis methods
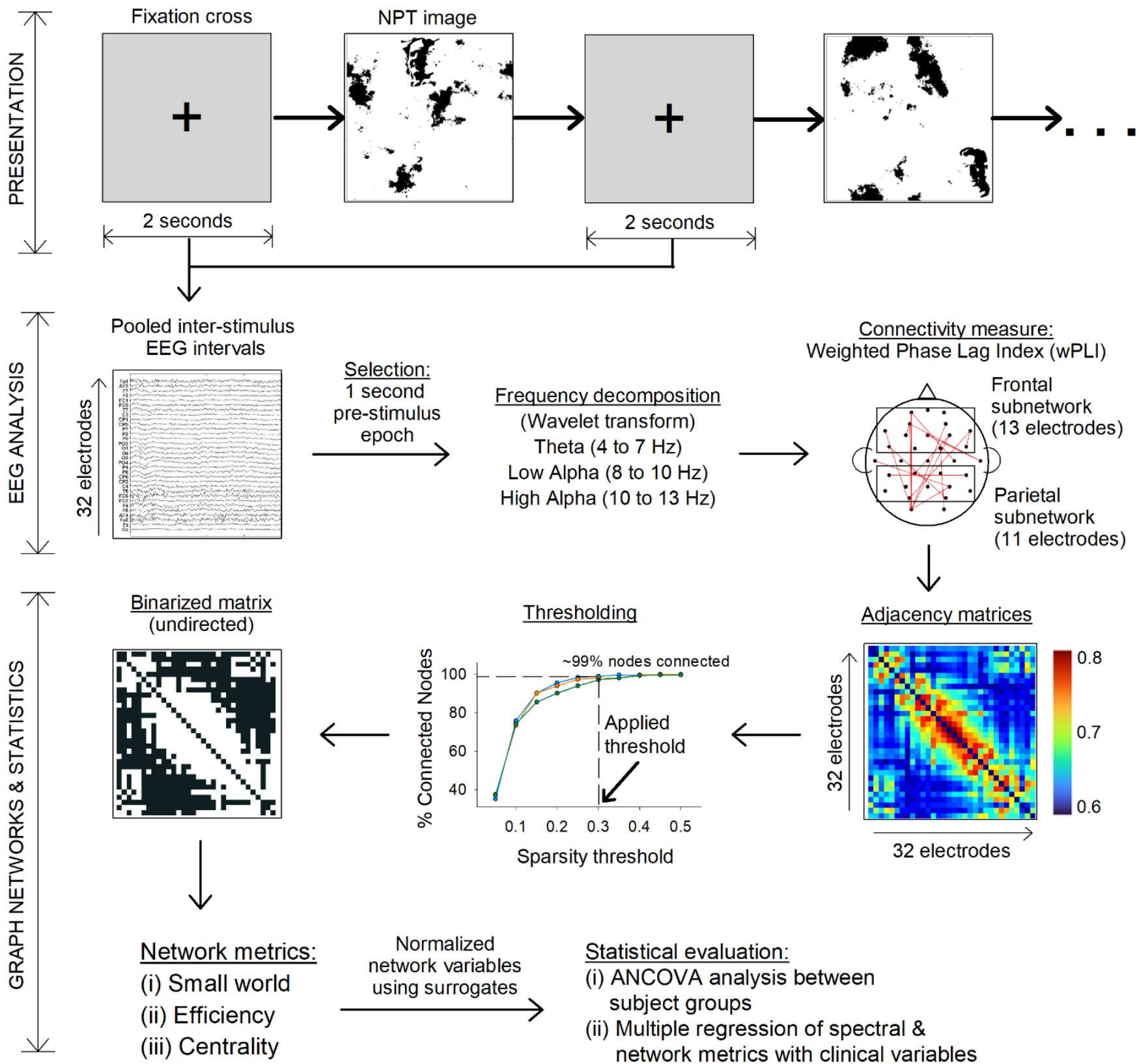

Legend Fig.1: NPT image = noise pareidolia test image, EEG = electroencephalography, ANCOVA = analysis of covariance. The workflow was divided into three parts as shown on left margins: Presentation of stimuli, EEG analysis and Graph network analysis. Presentation of stimuli comprised of 80 NPT images, each preceded by a fixation cross for 2 seconds which served as epochs for EEG analysis. EEG analysis involved preprocessing and wPLI calculation for theta, low-alpha and high-alpha band frequencies. Finally graph network were calculated based on binarized matrices obtained using wPLI as edges and EEG electrodes as nodes. Line-plot shown in 
medRxiv preprint doi: https://doi.org/10.1101/2020.12.09.20246850; this version posted December 11 , 2020. The copyright holder for this

preprint (which was not certified by peer review) is the author/funder, who has granted medRxiv a license to display the preprint in perpetuity.

It is made available under a CC-BY 4.0 International license .

thresholding represent the 3 groups that were tested. Statistical comparisons were subsequently performed for spectral and network measures between the three participant groups.

Each NPT image was preceded by a fixation-cross for $2 \mathrm{~s}$ on the monitor on which the subjects were asked to focus. EEG data were epoched from $-2000 \mathrm{~ms}$ to $0 \mathrm{~ms}$, with 0 being the onset of NPT image. To avoid any stimulus-onset related potential from the fixation-cross image, the first 1000ms was discarded. To normalize the recordings, for each subject, the entire epoch was then baseline corrected by its mean value, and wavelet transformed (Morlet) to obtain theta $(4-7 \mathrm{~Hz})$, low-alpha $(8-10 \mathrm{~Hz})$ and high-alpha $(10-13 \mathrm{~Hz})$ frequency bands. In our formulation of graph networks, we analyzed (i) global networks - defined by all 32 electrodes ('nodes'), and (ii) local measures - pre-defined via 13 frontal and 11 parietal electrodes. Frontal electrodes comprised of Fp1, AF3, F7, F3, FC1, FC5, FC6, FC2, F4, F8, AF4, Fp2 and Fz, whereas parietal area included CP1, CP5, P7, P3, Pz, PO3, PO4, P4, P8, CP6 and CP2 electrodes according to Biosemi cap-coordinate system. This selection was motivated by our pre-defined hypothesis and prior literature $(10,34)$ with respect to the involvement of frontoparietal networks in target search-and-detect paradigms.

To evaluate graph network properties for each frequency band, we utilized the weighted phase lag index (wPLI) as a measure of network connectivity. True neural interaction between two sources (here, the sensor space) show a coherent relationship when their time-series information is synchronized. wPLI provides a measure of this relationship between the sensor pairs to define cortical signals that are independent of volume conduction and exclude zero-lag connections caused due to spurious uncorrelated noise, thereby improving statistical power to identify phase synchronizations $(35,36)$. Intuitively, wPLI estimates the interaction between electrode pairs and quantifies the functional coupling between brain regions. wPLI values were calculated for theta (4-7Hz), lowalpha (8-10Hz) and high-alpha bands (10-13Hz) using Welch's power spectrum density(37), and served as 'edges' between the network pairs. For each subject, a 32x32 node-to-node adjacency matrix was obtained which were subsequently binarized to create undirected graphs for analysis. A crucial step in binarization is the application of thresholds to the adjacency matrices. Since threshold setting is often arbitrary(38), to obtain consistent results, we calculated the shortest path lengths between interconnected nodes for a range of thresholds and selected the one in which the nodes were connected approx. $99 \%$ of the time.

\section{Graph network indices}

Relevant to our hypothesis, we evaluated small-world properties (normalized clustering coefficient and normalized characteristic path length), efficiency (global and local sub-networks) and centrality (degree and betweenness centrality). The clustering coefficient is a measure of functional segregation between locally associated nodes and provides the likelihood that a node is connected by its neighbors. The characteristic path length is the average shortest path length between all possible pairs of nodes within the network and outlines the integration of information from different brain regions. Both the above indices were normalized using 100 random 
surrogate networks (to obtain Gamma and Lambda values respectively)(39). Efficiency of a graph defines the ability of information exchange within the network. Whereas global efficiency illustrates parallel information processing with a high integration of nodes, local efficiency is the averaged global efficiency within a sub-network of locally selected nodes which illustrates the tolerance of information exchange when a locally connected node is eliminated(27). Centrality measures the effectiveness of a node in information transfer within the network. Here, degree centrality defines the importance of a node(s) and its direct impact on adjacent brain areas. In our formulation of binarized graphs, the degree centrality illustrated the number of connections of each node to all other nodes in the graph. We also evaluated the betweenness centrality which provides a quantification of the node that acts as a bridge between two other connected nodes along its shortest path length. The shortest path length was the smallest number of connections between two nodes and was utilized not only to calculate various network measures, but also to define the sparsity threshold(40).

\section{Statistical analysis}

Differences between demographic and neuropsychological tests were reported using Kruskal Wallis test. For significant p-values, Dunn's post-hoc tests (for unequal groups) were performed between HC, PDnP and PDP groups. To report differences between patient groups (PDnP and PDP), Student's t-test or Mann Whitney-U test were performed.

For each spectral and graph network metric, between-group differences were evaluated using ANCOVA analysis on groups (HC, PDnP and PDP) with the addition of age and MoCA scores as nuisance covariates. These covariates were applied based on the fact that cortical activity, especially graph networks, are contingent on agerelated cognitive differences(41). Assumptions of normality and homogeneity were performed using ShapiroWilk's test and Levene's test respectively, with the test statistic set to 0.05. For responses that did not achieve normality, non-parametric ANOVA was performed. Statistical significance was set to $\mathrm{p}<0.05$ with subsequent post-hoc Tukey test performed for each significant dependent variable, adjusted for family-wise comparisons.

Since the aforementioned cortical metrics were calculated specifically for the NPT, we evaluated if these results could be envisioned for other cognitive or visuospatial tests. We therefore implemented a multiple linear regression for the three groups with neuropsychological tests as the clinical dependent variable; and age, EEG spectral power and graph indices as independent variables. Significance for the regression ANOVA model was set to 0.05 .

EEG preprocessing and epoching was implemented with an open source toolbox, Brainstorm(42). wPLI indices were calculated using Hermes toolbox(37), the resulting output used as edge weights for network construction using Gretna toolbox(43). Statistical analysis was performed on JASP(44). All other offline analysis and graphing of data were done using Matlab 2017b. Data analyzed in this study will be made available from the corresponding author upon reasonable request. 
medRxiv preprint doi: https://doi.org/10.1101/2020.12.09.20246850; this version posted December 11, 2020. The copyright holder for this preprint (which was not certified by peer review) is the author/funder, who has granted medRxiv a license to display the preprint in perpetuity.

\section{Results}

It is made available under a CC-BY 4.0 International license .

Demographic characteristics of participants are summarized in Table-1. In brief, PD patients susceptible to pareidolias (PDP) were older and under-performed on neuropsychological tests.

Table-1 - Demographic and neuropsychological assessment

\begin{tabular}{|c|c|c|c|c|c|}
\hline Demography & $\mathbf{H C}(\mathrm{N}=10)$ & $\operatorname{PDnP}(\mathrm{N}=11)$ & $\mathbf{P D P}(\mathrm{N}=10)$ & p-value & $\begin{array}{l}\text { Significance } \\
\text { (Dunn's test) }\end{array}$ \\
\hline Age (years) & $69.7 \pm 9.4$ & $65.6 \pm 9.4$ & $75.8 \pm 1.9$ & 0.021 & $\mathrm{PDP}>\mathrm{PDnP}$ \\
\hline $\operatorname{Sex}(M: F)$ & $6: 4$ & $5: 6$ & $5: 5$ & & \\
\hline $\begin{array}{c}\text { Disease duration } \\
\text { (years) }\end{array}$ & - & $6.7 \pm 4.0$ & $9.7 \pm 4.6$ & $0.133^{\mathrm{a}}$ & \\
\hline LEDD (mg) & - & $523.4 \pm 360.9$ & $819.6 \pm 523.0$ & $0.117^{\mathrm{b}}$ & \\
\hline MDS-UPDRS I & - & $12.3 \pm 7.7$ & $13.7 \pm 7.2$ & $0.687^{\mathrm{a}}$ & \\
\hline MDS-UPDRS III & - & $28.6 \pm 13.4$ & $29.1 \pm 13.4$ & $0.938^{\mathrm{a}}$ & \\
\hline MMSE & - & $27.0 \pm 2.8$ & $27.7 \pm 3.0$ & $0.589^{b}$ & \\
\hline MoCA & $27.0 \pm 1.5$ & $23.9 \pm 3.8$ & $21.0 \pm 3.5$ & $<0.001$ & $\mathrm{HC}>\mathrm{PDP}$ \\
\hline JART & $112 \pm 10.7$ & $106 \pm 28.2$ & $107 \pm 10.7$ & 0.78 & \\
\hline FAB & $17.8 \pm 0.4$ & $15.1 \pm 2.0$ & $14.8 \pm 1.9$ & $<0.001$ & $\begin{array}{c}\mathrm{HC}>\mathrm{PDP} / \\
\mathrm{PDnP}\end{array}$ \\
\hline JLO & $13.5 \pm 2.1$ & $11.6 \pm 3.3$ & $8.6 \pm 4.5$ & 0.01 & $\mathrm{HC}>\mathrm{PDP}$ \\
\hline $\begin{array}{c}\text { Pareidolia score } \\
\text { NPT }\end{array}$ & $1(0,4)$ & $1(0,4.7)$ & $24(16,42)$ & $<0.001$ & $\begin{array}{c}\mathrm{PDP}>\mathrm{HC} / \\
\mathrm{PDnP}\end{array}$ \\
\hline
\end{tabular}

Table-1 legend: $H C=$ Healthy controls, $P D n P=$ Parkinson's disease non-pareidolia type, $P D P=P$ arkinson's disease pareidolia type, $L E D D=$ Levodopa equivalent daily dose, MDS-UPDRS = Movement Disorder Society - Unified Parkinson's disease rating scale, MMSE = Mini-mental state examination, MoCA = Montreal cognitive assessment, JART = Japanese adult reading test, FAB = Frontal assessment battery, JLO= Judgment of line orientation test, $N P T=$ Noise pareidolia test

NPT scores shown are medians (interquartile range). All other scores are presented as means \pm standard deviation. ${ }^{a}$ Student's t-test, ${ }^{b}$ Mann Whitney-U test 
For EEG analysis of the pre-stimulus phase, a grand total of 780 trials for HC, 840 for PDnP and 755 for PDP group were analyzed. Spectral analysis for theta, low-alpha and high-alpha bands showed no significant differences between the groups. However, low-alpha frequencies in frontal area exhibited a trend towards higher spectral power for the PDP group $(\mathrm{p}=0.06)$. Both global and local wPLI showed no significant differences between the groups (Table-2).

Calculating the shortest path lengths for a series of ten sparsity thresholds ranging from 0.05 to 0.5 , incrementing every 0.05, we fixed the threshold at 0.3 wherein the nodes were connected approx. 99\% of the time (Fig.1, Sparsity threshold). Subsequent ANCOVA analysis of the graph networks revealed significant differences for low-alpha frequency band (Table-2), with no differences in theta and high-alpha activity (Supplementary Table1). In general, low-alpha band changes between $\mathrm{HC}$ and PDnP groups were inconsequential. However, PDP group showed a statistically higher normalized clustering coefficient $\left(\mathrm{PDP}_{\mathrm{Gamma}}=1.04 \pm 0.03 \mathrm{vs} . \mathrm{PDnP} \mathrm{Gamma}=0.94 \pm 0.03\right.$ or $\mathrm{HC}_{\mathrm{Gamma}}=0.93 \pm 0.03$, adjusted means \pm error), with no significant differences in the normalized path lengths. Locally, parietal electrodes showed a higher nodal efficiency which served to demonstrate the higher information exchange of the interconnected network in the parietal area during the pre-stimulus phase. Furthermore, PDP group showed significantly low degree centrality in frontal electrodes suggestive of a dispersed or disconnected network. Topological illustration of graph indices is shown in Fig.2.

Table-2 - Analysis of covariance on spectral and graph network measures for low-alpha frequency band

\begin{tabular}{|c|c|c|c|c|}
\hline \multirow{2}{*}{ Measure } & \multirow{2}{*}{ Global } & \multicolumn{2}{|c|}{ Local } & \multirow{2}{*}{$\begin{array}{c}\text { Post-hoc } \\
\text { comparisons }\end{array}$} \\
\hline & & Frontal & Parietal & \\
\hline Mean power $(\mathrm{dB})^{\dagger}$ & $\begin{array}{c}\mathrm{F}_{(2,28)}=5.05 \\
\mathrm{p}=0.08\end{array}$ & $\begin{array}{c}\mathrm{F}_{(2,26)}=2.99 \\
\mathrm{p}=0.06\end{array}$ & $\begin{array}{c}\mathrm{F}_{(2,28)}=2.27 \\
\mathrm{p}=0.12\end{array}$ & - \\
\hline Mean wPLI & $\begin{array}{c}\mathrm{F}_{(2,26)}=0.25 \\
\mathrm{p}=0.77\end{array}$ & $\begin{array}{c}\mathrm{F}_{(2,26)}=0.63 \\
\mathrm{p}=0.54\end{array}$ & $\begin{array}{c}\mathrm{F}_{(2,26)}=0.10 \\
\mathrm{p}=0.90\end{array}$ & - \\
\hline $\begin{array}{c}\text { Normalized clustering } \\
\text { coefficient }\end{array}$ & $\begin{array}{c}\mathrm{F}_{(2,26)}=3.38 \\
p=0.050 *\end{array}$ & $\begin{array}{c}\mathrm{F}_{(2,26)}=0.06 \\
\mathrm{p}=0.94\end{array}$ & $\begin{array}{c}\mathrm{F}_{(2,26)}=3.14 \\
\mathrm{p}=0.06\end{array}$ & $\begin{array}{c}\mathrm{PDP}>\mathrm{PDnP}, \\
\mathrm{p}_{\text {tukey }}=0.06\end{array}$ \\
\hline Normalized path length & $\begin{array}{c}\mathrm{F}_{(2,26)}=1.52 \\
\mathrm{p}=0.24\end{array}$ & $\begin{array}{c}\mathrm{F}_{(2,26)}=0.83 \\
\mathrm{p}=0.45\end{array}$ & $\begin{array}{c}\mathrm{F}_{(2,26)}=0.44 \\
\mathrm{p}=0.65\end{array}$ & - \\
\hline Efficiency & $\begin{array}{c}\mathrm{F}_{(2,26)}=0.16 \\
\mathrm{p}=0.85\end{array}$ & $\begin{array}{c}\mathrm{F}_{(2,26)}=0.98 \\
\mathrm{p}=0.34\end{array}$ & $\begin{array}{c}\mathrm{F}_{(2,26)}=3.39 \\
p=0.049 *\end{array}$ & $\begin{array}{l}\text { PDP }>\text { PDnP, } \\
\mathrm{p}_{\text {tukey }}=0.050\end{array}$ \\
\hline Degree centrality & $\begin{array}{c}\mathrm{F}_{(2,26)}=0.12 \\
\mathrm{p}=0.89\end{array}$ & $\begin{array}{c}\mathrm{F}_{(2,26)}=6.47 \\
p=0.005 *\end{array}$ & $\begin{array}{c}\mathrm{F}_{(2,26)}=1.63 \\
\mathrm{p}=0.21\end{array}$ & $\begin{array}{l}\mathrm{PDP}<\mathrm{PDnP}, \\
\mathrm{p}_{\text {tukey }}=0.005\end{array}$ \\
\hline Betweenness centrality & $\begin{array}{c}\mathrm{F}_{(2,26)}=0.24 \\
\mathrm{p}=0.78\end{array}$ & $\begin{array}{c}\mathrm{F}_{(2,26)}=0.97 \\
\mathrm{p}=0.39\end{array}$ & $\begin{array}{c}\mathrm{F}_{(2,26)}=0.35 \\
\mathrm{p}=0.70\end{array}$ & - \\
\hline
\end{tabular}


medRxiv preprint doi: https://doi.org/10.1101/2020.12.09.20246850; this version posted December 11, 2020. The copyright holder for this preprint (which was not certified by peer review) is the author/funder, who has granted medRxiv a license to display the preprint in perpetuity.

It is made available under a CC-BY 4.0 International license .

Table-2 legend: $d B=$ decibels, $w P L I=$ weighted phase lag index, PDnP = Parkinson's disease non-pareidolia type, $P D P=$ Parkinson's disease pareidolia type

${ }^{\dagger}$ Addition of covariates (Age and MoCA) failed tests for equal variances. One-way ANOVA (without covariates) showed significant differences in mean power at global level $(p=0.037)$ and for frontal electrodes $(p=0.020)$, with post-hoc tests showing mean power for PDP group > HC or PDnP groups.

Non-parametric Kruskal-Wallis ANOVA

*For all significant comparisons, post-hoc tests (Tukey) are shown in the right-most column.

\section{Figure 2 - Spectral and topological structures of graph indices for Low-alpha band}

\section{A. EEG low-alpha power}

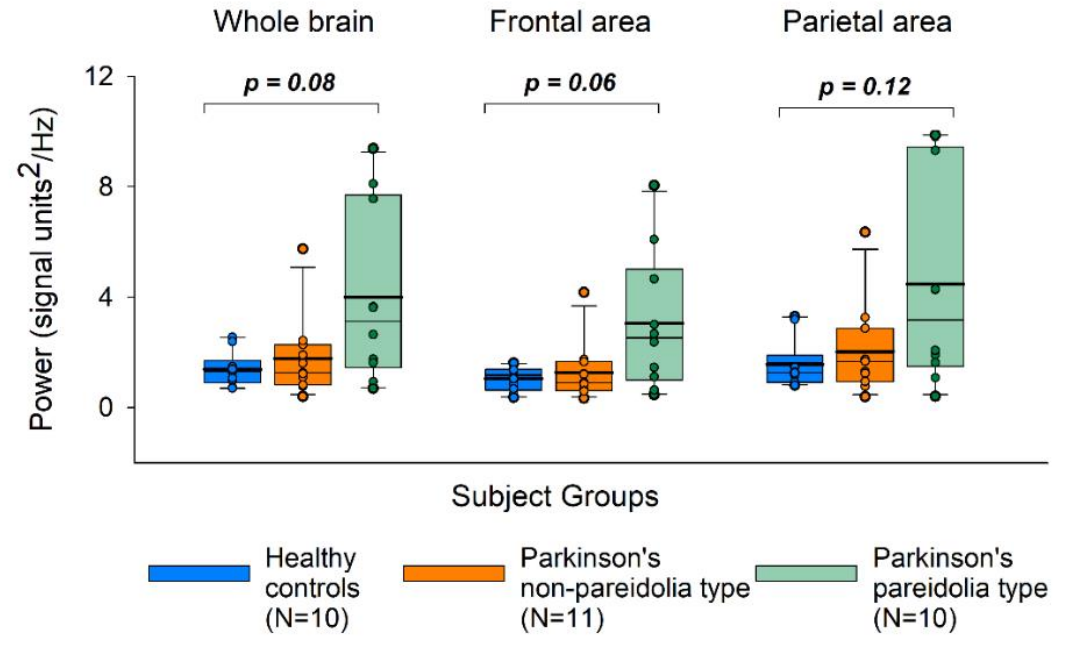

B. Graph network metrics for low-alpha band

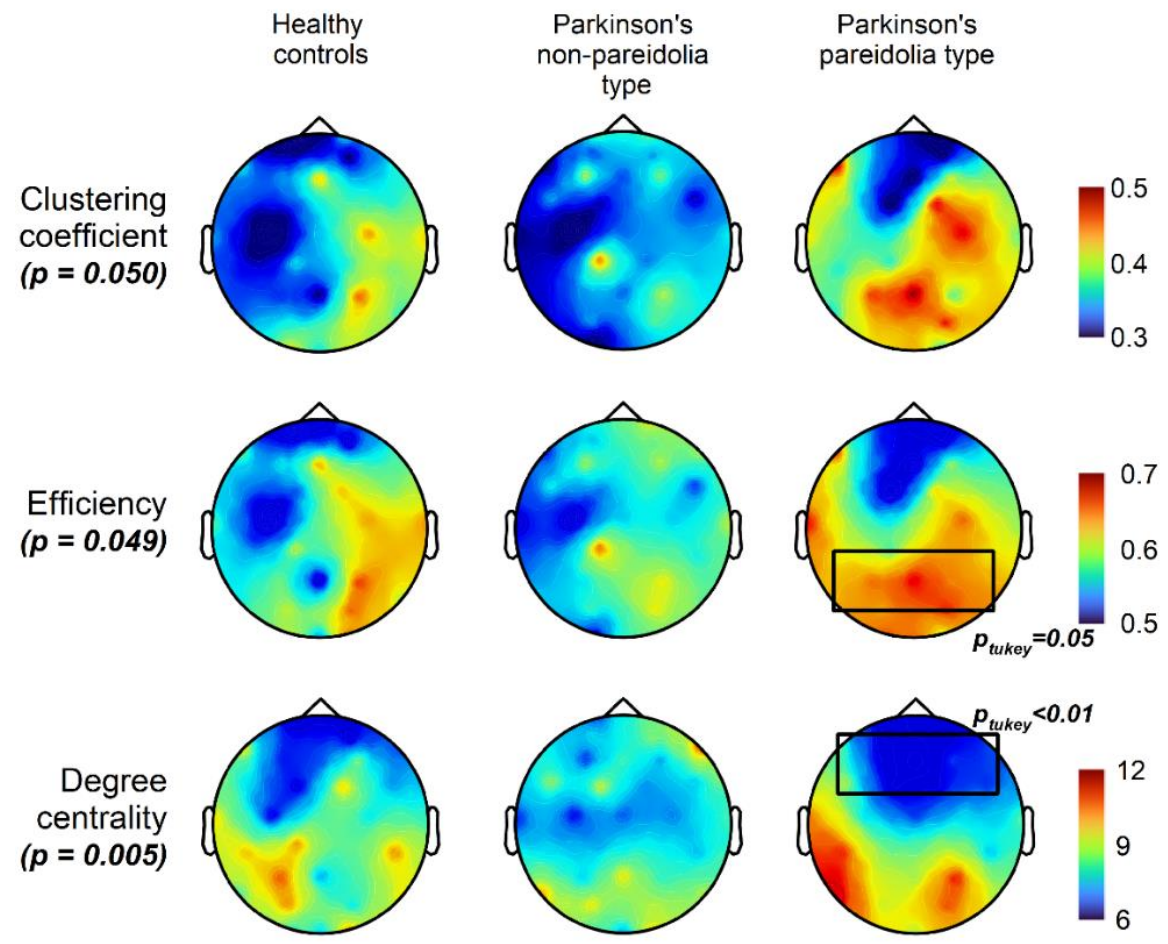


medRxiv preprint doi: https://doi.org/10.1101/2020.12.09.20246850; this version posted December 11 , 2020. The copyright holder for this preprint (which was not certified by peer review) is the author/funder, who has granted medRxiv a license to display the preprint in perpetuity.

It is made available under a CC-BY 4.0 International license .

(A) Boxplot (with point-plot overlap) shows low-alpha (8 to 10Hz) frequency spectrum for whole brain, frontal and parietal electrodes separately. Within the box, thin black line represents the median whereas thick black line represents the mean. Whole brain refers to full set of 32 electrodes. Frontal electrodes comprised of 13 anterior electrodes, whereas 11 posterior electrodes were included for parietal region. p-values shown are results of ANCOVA analysis (described in Table-2).

(B) Topological plot showing significant differences of key graph indices. Warm colors show increased whereas cool colors show decreased nodal values for the respective indices. p-values shown are results of ANCOVA analysis (Table-2). Boxed area (in black) are significant regional post-hoc comparisons.

Multiple linear regression between clinical variables and spectral/network metrics are shown in Table-3. Results of regression analysis indicated that the spectral and graph indices were significantly correlated to pareidolia scores $\left(\mathrm{R}^{2}=0.43, p=0.011\right)$ and weakly to $\mathrm{FAB}$ scores $\left(\mathrm{R}^{2}=0.20, \mathrm{p}=0.052\right)$. The regression coefficients for the independent variables are described in Supplementary Table-2.

Table-3 - Multiple linear regression of low-alpha spectral and graph indices for neuropsychological tests

\begin{tabular}{|c|c|c|c|c|c|c|c|}
\hline & $\begin{array}{l}\text { Independent } \\
\text { variables }\end{array}$ & $\begin{array}{c}\text { Clinical } \\
\text { variable }\end{array}$ & F-value & p-value & $\mathbf{R}^{2}$ & $\begin{array}{c}\text { Adjusted } \\
\mathbf{R}^{2}\end{array}$ & $\begin{array}{l}\text { Durbin- } \\
\text { Watson } \\
\text { statistic }\end{array}$ \\
\hline \multirow[t]{5}{*}{$\begin{array}{l}\text { (i) } \\
\text { (ii) } \\
\text { (iii) }\end{array}$} & \multirow{5}{*}{$\begin{array}{l}\text { Age } \\
\text { Power }(\mathrm{dB}) \\
\text { Normalized } \\
\text { clustering } \\
\text { coefficient } \\
\text { Parietal local } \\
\text { nodal efficiency } \\
\text { Frontal region } \\
\text { degree centrality }\end{array}$} & MoCA & $\mathrm{F}_{(5,25)}=0.96$ & 0.461 & 0.16 & -0.007 & $\begin{array}{c}1.80 \\
\mathrm{p}=0.53\end{array}$ \\
\hline & & JART & $\mathrm{F}_{(5,25)}=1.03$ & 0.420 & 0.17 & 0.006 & $\begin{array}{c}2.25 \\
\mathrm{p}=0.51\end{array}$ \\
\hline & & FAB & $\mathrm{F}_{(5,25)}=2.57$ & 0.052 & 0.34 & 0.208 & $\begin{array}{c}1.39 \\
p=0.06\end{array}$ \\
\hline & & JLO & $\mathrm{F}_{(5,25)}=1.51$ & 0.222 & 0.23 & 0.079 & $\begin{array}{c}1.9 \\
\mathrm{p}=0.71\end{array}$ \\
\hline & & $N P T$ & $F_{(5,25)}=3.78$ & 0.011 & 0.43 & 0.316 & $\begin{array}{c}1.65 \\
p=0.28\end{array}$ \\
\hline
\end{tabular}

Table-3 legend: $d B=$ decibels, $F A B=$ Frontal assessment battery, JART = Japanese adult reading test MoCA = Montreal cognitive assessment, $J L O=$ Judgment of line orientation test, NPT = Noise pareidolia test 


\section{Discussion}

We investigated how large-scale network organization is altered prior to stimulus onset in PD patients susceptible to pareidolias. In patients who demonstrate pareidolic misperceptions, we found that: (i) the pre-stimulus lowalpha power tends to be higher in frontal cortex, (ii) there are notable changes in global and local network properties during anticipation of stimuli, and (iii) the spectral and network indices are characteristic of pareidolic expression on the noise pareidolia test (NPT).

Face detection on the NPT necessitates an active search-and-detect effort requiring configural face processing and a top-down integration of facial features(10). While these images serve as sensory deprived ambiguous stimuli, a subset of PD patients consciously misperceive noisy patches as faces, likely due to abnormal perceptual biases(13). In our experiment during the pre-stimulus phase, this misrepresentation was observed as a nearsignificant increase in low-alpha spectral power in the frontal electrodes. In literature, alpha power codes stimulus identity(45). Conscious perception of low-level information reflecting top-down visual processing has been attributed to higher pre-stimulus low-alpha power(46). Anticipation of relevant stimuli increases alpha activity, its strength proportional to the saliency of the stimuli(47). Given that cortical low-alpha power represents the attentional dynamics within the cortico-cortical loops $(45,48)$, our findings are suggestive of a diversion of attentional resources towards internal processing to code non-relevant stimulus identity in patients susceptible to pareidolias. However pre-stimulus low-alpha power is increased globally i.e. in frontal, parietal and occipital electrodes when targets are actively perceived(46). Our results partially support this finding since we did not find any differences in the posterior parietal electrodes which have a critical role in pre-stimulus internally generated processes(49). This discrepancy could be attributed to a diverse pathology seen in pareidolias, which are known to occur at different stages of PD involving both cortical (frontal or parieto-occipital cortex) and subcortical structures (upper brainstem or thalamus)(7).

Pareidolic misperceptions, like hallucinations, are an eventuality of global cortical network dysfunction(8). Pertaining to global network level deficits in PD, we explored small-world properties which are commonly affected in neuropsychiatric diseases(39). The increased normalized clustering coefficient reported in the PDP group suggests a heightened integration of information during pre-stimulus phase. Visualization of the topology showed a delineation of clusters in the parietal cortex (Fig.2). Furthermore, these posterior nodes also revealed a high nodal efficiency when compared with HC or PDnP groups. As a proxy to small-worldness(50), these indices demonstrate an efficient information transfer within the parietal network. Within the framework of low-alpha band frequency, our findings suggests a reduced disengagement of posterior cortex during non-relevant stimulus anticipation(15). This cortical signature in the posterior electrodes reflecting focused intentional awareness(49) is a persisting feature for ambiguous stimuli, since similar findings have also been observed in PD patients with 
medRxiv preprint doi: https://doi.org/10.1101/2020.12.09.20246850; this version posted December 11 , 2020. The copyright holder for this

hallucinations via bi-stable percept paradigms that demonstrate the altered communication between the default mode network (DMN) and the dorsal attentional network (DAN)(28,51).

The degree centrality is an index of how well the nodes are connected, whereas betweenness centrality is a measure of the node connected to other independent node clusters(40). We observed that patients experiencing pareidolias had significantly lower degree centrality in the frontal electrodes without any change in betweenness centrality. Intuitively, this signifies a higher number of discrete nodes with low connections within the frontal cortex. According to scale-free distributions, in sparsely connected networks, these nodes represent a low-linkage with an absence of hub characteristics(52). Psychophysiologically, with a concomitant high frontal spectral power, this could imply the maintenance of cortical excitability within the network to process imminent visual stimuli irrespective of its saliency(46). The fallout of this process is a breakdown of communication between the DMN and DAN that modulates visuo-perceptual priors(28), disordered frontal attention networks that create an abnormal competition with weak stimuli(53) or an increased dependence on top-down signals leading to the development of misperceptions(54).

We found that the spectral and graph indices were significantly correlated only to pareidolia scores in our participant groups. Our selection of neuropsychological tests was to examine the effect of altered networks in visuo-perception that overlap with cognitive (MoCA, JART), executive (FAB), visuo-spatial and visuoconstruction function (JLO). While FAB showed a trend towards significance, the less than significant findings from JLO were notable since posterior parietal cortex lesions often show lower scores on JLO(55). It is therefore likely that the high clustering coefficient and nodal efficiency we observed in the parietal electrodes could be an epiphenomenon observed due to stimulus anticipation process. Since regression did not affect the outcome of other neuropsychological tests, the above findings signify a higher influence of fronto-cortical network structure on the outcome of pareidolic misperception. Regardless, profiling disease pathology in neuropsychiatric disorders in terms of increased or decreased connectivity purely on the basis of graph theory must be treated with caution due to overlaps in domain-specific tasks with different brain areas(50).

\section{Limitations}

There are some limitations to this study. The scope of this report was mainly to demonstrate the cortical dynamics via EEG though other behavioral measures may be relevant. Eye-tracking metrics such as change in lowfrequency pupillary power is suggested to be crucial during stimulus anticipation in patients experiencing pareidolias(56). The effect of negative mood is also known to affect the outcomes of the NPT(13). We also avoided sub-classifying the pre-stimulus responses into face, noise, pareidolias and missed images due to the skewed nature of the NPT (fewer face stimuli than noise). Furthermore, the saliency of Mooney face stimuli within the NPT was not trivial, and considering the length of the experiment, some degree of temporal variability of the EEG was unavoidable(57). The effect of levodopa(58) was not systematically studied except that the NPT 
medRxiv preprint doi: https://doi.org/10.1101/2020.12.09.20246850; this version posted December $11,2020$. The copyright holder for this preprint (which was not certified by peer review) is the author/funder, who has granted medRxiv a license to display the preprint in perpetuity.

It is made available under a CC-BY 4.0 International license .

was always performed during 'ON' state of medication. We also did not report here crucial subjective experiences

of patients (images that were responded to as animals etc.) which may be relevant to the concept of illusionary responses. Therefore, more data by increasing sample sizes are necessary to understand conclusively the effects of pareidolia.

Statistically, the data distribution followed gaussian allowing us to control our analysis methodologies for age and cognitive levels. Although addition of other covariates (eg. JLO, FAB) increased the statistical significance of the tests (data not shown), we avoided their inclusion due to a paucity of prior literature on their effects on graph networks. Our mode of comparing normal and diseased networks of similar size by fixing thresholds for binarized graphs is in line with prior literature although weighted graphs could be an informative substitute to compare such conditions. Addressing these issues in the future would be beneficial not only for cross-sectional studies but also for studies that focus on the longitudinal evolution of pareidolia in the culmination of hallucinations/psychosis in PD.

\section{Conclusions}

Pareidolias in PD are a consequence of an abnormal top-down modulation of visual processing(10) which are defined by frontal low-alpha spectral and network alterations in the pre-stimulus phase due to a dissonance between patients' internally generated mental-processing with external stimuli. As a surrogate of visual hallucinations, our result highlights the impact of pareidolias on the frontal cortex in susceptible PD populations. Further work is needed to ascertain the burden of cortico-subcortical structures in the pathogenesis and maintenance of such symptoms in PD.

\section{Acknowledgements}

We express our sincere gratitude to the patients who participated in this study, and to Mr. Toshiaki Fujimoto and the members of the Minoh Senri-Chuo Rotary Club, Japan for their undivided support. We also thank Dr. Maki Suzuki and Dr. Hiroyuki Watanabe for their advice during the development process.

\section{Funding}

G.S.R was supported by the Grants-in-Aid for Interdisciplinary Research, JSPS, Japan. H.M was supported by Grants-in-Aid from the Research Committee of Central Nervous System Degenerative Diseases, Research on Policy Planning and Evaluation for Rare and Intractable Diseases, Health, Labor and Welfare Sciences Research Grants, the Ministry of Health, Labor and Welfare, Japan (Grant number KH39Q033a). 


\section{Authors' Roles}

It is made available under a CC-BY 4.0 International license .

Conceptualization - G.S.R., Y.K., T.S., N.H., E.M. and H.M.

Methodology - G.S.R., T.N. and Y.K.

Software, Validation - G.S.R., Y.K. and T.S.

Formal analysis, Data curation - G.S.R., N.H., T.N. and Y.K.

Writing - original draft preparation - G.S.R.

Writing - review \& editing - Y.K., T.S., T.N., N.H., M.M., E.M and H.M.

Supervision, Funding acquisition - G.S.R. and H.M.

\section{Bibliography}

1. ffytche DH, Creese B, Politis M, Chaudhuri KR, Weintraub D, Ballard C, et al. The psychosis spectrum in Parkinson disease. Nat Rev Neurol. 2017 Feb;13(2):81-95.

2. Barnes J. Visual hallucinations in Parkinson's disease: a review and phenomenological survey. J Neurol Neurosurg Psychiatry. 2001 Jun 1;70(6):727-33.

3. Kulick CV, Montgomery KM, Nirenberg MJ. Comprehensive identification of delusions and olfactory, tactile, gustatory, and minor hallucinations in Parkinson's disease psychosis. Parkinsonism Relat Disord. 2018;54:40-5.

4. Lenka A, Pagonabarraga J, Pal PK, Bejr-Kasem H, Kulisvesky J. Minor hallucinations in Parkinson disease. Neurology. 2019 Aug 6;93(6):259.

5. Uchiyama M, Nishio Y, Yokoi K, Hosokai Y, Takeda A, Mori E. Pareidolia in Parkinson's disease without dementia: A positron emission tomography study. Parkinsonism Relat Disord. 2015 Jun;21(6):603-9.

6. Yokoi K, Nishio Y, Uchiyama M, Shimomura T, Iizuka O, Mori E. Hallucinators find meaning in noises: pareidolic illusions in dementia with Lewy bodies. Neuropsychologia. 2014 Apr;56:245-54.

7. Nishio Y, Yokoi K, Uchiyama M, Mamiya Y, Watanabe H, Gang M, et al. Deconstructing psychosis and misperception symptoms in Parkinson's disease. J Neurol Neurosurg Psychiatry. 2017 Sep;88(9):722-9.

8. O'Brien J, Taylor JP, Ballard C, Barker RA, Bradley C, Burns A, et al. Visual hallucinations in neurological and ophthalmological disease: pathophysiology and management. J Neurol Neurosurg Psychiatry. 2020 May;91(5):512-9. 
medRxiv preprint doi: https://doi.org/10.1101/2020.12.09.20246850; this version posted December 11, 2020. The copyright holder for this preprint (which was not certified by peer review) is the author/funder, who has granted medRxiv a license to display the preprint in perpetuity. It is made available under a CC-BY 4.0 International license .

9. Uchiyama M, Nishio Y, Yokoi K, Hirayama K, Imamura T, Shimomura T, et al. Pareidolias: complex visual illusions in dementia with Lewy bodies. Brain. 2012 Aug 1;135(8):2458-69.

10. Revankar GS, Hattori N, Kajiyama Y, Nakano T, Mihara M, Mori E, et al. Ocular fixations and presaccadic potentials to explain pareidolias in Parkinson's disease. Brain Commun. 2020;2(1):fcaa073.

11. Flowers KA, Robertson C. Perceptual Abnormalities in Parkinson's Disease: Top-Down or Bottom-Up Processes? Perception. 1995 Oct 1;24(10):1201-21.

12. Corlett PR, Horga G, Fletcher PC, Alderson-Day B, Schmack K, Powers AR. Hallucinations and Strong Priors. Trends Cogn Sci. 2019 Feb 1;23(2):114-27.

13. Watanabe H, Nishio Y, Mamiya Y, Narita W, Iizuka O, Baba T, et al. Negative mood invites psychotic false perception in dementia. PloS One. 2018;13(6):e0197968.

14. Linkenkaer-Hansen K, Nikulin VV, Palva S, Ilmoniemi RJ, Palva JM. Prestimulus oscillations enhance psychophysical performance in humans. J Neurosci Off J Soc Neurosci. 2004 Nov 10;24(45):10186-90.

15. Dijk H van, Schoffelen J-M, Oostenveld R, Jensen O. Prestimulus Oscillatory Activity in the Alpha Band Predicts Visual Discrimination Ability. J Neurosci. 2008 Feb 20;28(8):1816-23.

16. Mathewson KE, Gratton G, Fabiani M, Beck DM, Ro T. To see or not to see: prestimulus alpha phase predicts visual awareness. J Neurosci Off J Soc Neurosci. 2009 Mar 4;29(9):2725-32.

17. Arnau S, Löffler C, Rummel J, Hagemann D, Wascher E, Schubert A-L. Inter-trial alpha power indicates mind wandering. Psychophysiology. 2020;57(6):e13581.

18. Fink A, Benedek M. EEG alpha power and creative ideation. Neurosci Biobehav Rev. 2014 Jul;44(100):111-23.

19. Bartsch F, Hamuni G, Miskovic V, Lang PJ, Keil A. Oscillatory brain activity in the alpha range is modulated by the content of word-prompted mental imagery. Psychophysiology. 2015 Jun;52(6):727-35.

20. Cooper NR, Croft RJ, Dominey SJJ, Burgess AP, Gruzelier JH. Paradox lost? Exploring the role of alpha oscillations during externally vs. internally directed attention and the implications for idling and inhibition hypotheses. Int J Psychophysiol. 2003 Jan 1;47(1):65-74.

21. Shine JM, Halliday GM, Naismith SL, Lewis SJG. Visual misperceptions and hallucinations in Parkinson's disease: dysfunction of attentional control networks? Mov Disord Off J Mov Disord Soc. 2011 Oct;26(12):2154-9. 
medRxiv preprint doi: https://doi.org/10.1101/2020.12.09.20246850; this version posted December 11, 2020. The copyright holder for this preprint (which was not certified by peer review) is the author/funder, who has granted medRxiv a license to display the preprint in perpetuity.

It is made available under a CC-BY 4.0 International license .

22. Stoffers D, Bosboom JLW, Deijen JB, Wolters EC, Berendse HW, Stam CJ. Slowing of oscillatory brain activity is a stable characteristic of Parkinson's disease without dementia. Brain. 2007 Jul 1;130(7):184760.

23. Babiloni C, De Pandis MF, Vecchio F, Buffo P, Sorpresi F, Frisoni GB, et al. Cortical sources of resting state electroencephalographic rhythms in Parkinson's disease related dementia and Alzheimer's disease. Clin Neurophysiol. 2011 Dec 1;122(12):2355-64.

24. Schmiedt C, Meistrowitz A, Schwendemann G, Herrmann M, Basar-Eroglu C. Theta and alpha oscillations reflect differences in memory strategy and visual discrimination performance in patients with Parkinson's disease. Neurosci Lett. 2005 Nov 18;388(3):138-43.

25. Singh A, Richardson SP, Narayanan N, Cavanagh JF. Mid-frontal theta activity is diminished during cognitive control in Parkinson's disease. Neuropsychologia. 2018 Aug;117:113-22.

26. Onofrj M, Espay AJ, Bonanni L, Pizzi SD, Sensi SL. Hallucinations, somatic-functional disorders of PDDLB as expressions of thalamic dysfunction. Mov Disord. 2019;34(8):1100-11.

27. Sporns O. Structure and function of complex brain networks. Dialogues Clin Neurosci. 2013 Sep;15(3):247-62.

28. Shine JM, Muller AJ, O’Callaghan C, Hornberger M, Halliday GM, Lewis SJ. Abnormal connectivity between the default mode and the visual system underlies the manifestation of visual hallucinations in Parkinson's disease: a task-based fMRI study. Npj Park Dis. 2015 Apr 22;1(1):1-8.

29. Olde Dubbelink KTE, Hillebrand A, Stoffers D, Deijen JB, Twisk JWR, Stam CJ, et al. Disrupted brain network topology in Parkinson's disease: a longitudinal magnetoencephalography study. Brain. 2014 Jan 1;137(1):197-207.

30. Hassan M, Chaton L, Benquet P, Delval A, Leroy C, Plomhause L, et al. Functional connectivity disruptions correlate with cognitive phenotypes in Parkinson's disease. NeuroImage Clin. 2017 Mar 6;14:591-601.

31. Utianski RL, Caviness JN, van Straaten ECW, Beach TG, Dugger BN, Shill HA, et al. Graph theory network function in Parkinson's disease assessed with electroencephalography. Clin Neurophysiol Off J Int Fed Clin Neurophysiol. 2016 May;127(5):2228-36.

32. Mamiya Y, Nishio Y, Watanabe H, Yokoi K, Uchiyama M, Baba T, et al. The Pareidolia Test: A Simple Neuropsychological Test Measuring Visual Hallucination-Like Illusions. PloS One. 2016;11(5):e0154713. 
medRxiv preprint doi: https://doi.org/10.1101/2020.12.09.20246850; this version posted December 11, 2020. The copyright holder for this preprint (which was not certified by peer review) is the author/funder, who has granted medRxiv a license to display the preprint in perpetuity. It is made available under a CC-BY 4.0 International license .

33. Schwartzman D, Maravic K, Kranczioch C, Barnes J. Altered early visual processing components in hallucination-prone individuals. Neuroreport. 2008 Jun 11;19(9):933-7.

34. Nikolaev AR, Jurica P, Nakatani C, Plomp G, van Leeuwen C. Visual encoding and fixation target selection in free viewing: presaccadic brain potentials. Front Syst Neurosci. 2013;7:26.

35. Vinck M, Oostenveld R, van Wingerden M, Battaglia F, Pennartz CMA. An improved index of phasesynchronization for electrophysiological data in the presence of volume-conduction, noise and sample-size bias. NeuroImage. 2011 Apr 15;55(4):1548-65.

36. Imperatori LS, Betta M, Cecchetti L, Canales-Johnson A, Ricciardi E, Siclari F, et al. EEG functional connectivity metrics wPLI and wSMI account for distinct types of brain functional interactions. Sci Rep. 2019 Jun 20;9(1):8894.

37. Niso G, Bruña R, Pereda E, Gutiérrez R, Bajo R, Maestú F, et al. HERMES: Towards an Integrated Toolbox to Characterize Functional and Effective Brain Connectivity. Neuroinformatics. 2013 Oct $1 ; 11(4): 405-34$.

38. Langer N, Pedroni A, Jäncke L. The Problem of Thresholding in Small-World Network Analysis. PLOS ONE. 2013 Jan 3;8(1):e53199.

39. de Haan W, Pijnenburg YA, Strijers RL, van der Made Y, van der Flier WM, Scheltens P, et al. Functional neural network analysis in frontotemporal dementia and Alzheimer's disease using EEG and graph theory. BMC Neurosci. 2009 Aug 21;10(1):101.

40. Liu J, Li M, Pan Y, Lan W, Zheng R, Wu F-X, et al. Complex Brain Network Analysis and Its Applications to Brain Disorders: A Survey. De Domenico M, editor. Complexity. 2017 Oct $22 ; 2017: 8362741$.

41. Stumme J, Jockwitz C, Hoffstaedter F, Amunts K, Caspers S. Functional network reorganization in older adults: Graph-theoretical analyses of age, cognition and sex. NeuroImage. 2020 Jul 1;214:116756.

42. Tadel F, Baillet S, Mosher JC, Pantazis D, Leahy RM. Brainstorm: a user-friendly application for MEG/EEG analysis. Comput Intell Neurosci. 2011;2011:879716.

43. Wang J, Wang X, Xia M, Liao X, Evans A, He Y. GRETNA: a graph theoretical network analysis toolbox for imaging connectomics. Front Hum Neurosci. 2015;9:386.

44. JASP Team. JASP (Version 0.14), 2020. Available from: https://jasp-stats.org/ 
medRxiv preprint doi: https://doi.org/10.1101/2020.12.09.20246850; this version posted December 11, 2020. The copyright holder for this preprint (which was not certified by peer review) is the author/funder, who has granted medRxiv a license to display the preprint in perpetuity.

It is made available under a CC-BY 4.0 International license .

45. Klimesch W. Alpha-band oscillations, attention, and controlled access to stored information. Trends Cogn Sci. 2012 Dec 1;16(12):606-17.

46. Babiloni C, Vecchio F, Bultrini A, Luca Romani G, Rossini PM. Pre- and poststimulus alpha rhythms are related to conscious visual perception: a high-resolution EEG study. Cereb Cortex N Y N 1991. 2006 Dec;16(12):1690-700.

47. Barne LC, de Lange FP, Cravo AM. Prestimulus alpha power is related to the strength of stimulus representation. Cortex. 2020 Nov 1;132:250-7.

48. Pfurtscheller G, Lopes da Silva FH. Event-related EEG/MEG synchronization and desynchronization: basic principles. Clin Neurophysiol. 1999 Nov 1;110(11):1842-57.

49. Benedek M, Schickel RJ, Jauk E, Fink A, Neubauer AC. Alpha power increases in right parietal cortex reflects focused internal attention. Neuropsychologia. 2014 Apr;56(100):393-400.

50. Bullmore ET, Bassett DS. Brain graphs: graphical models of the human brain connectome. Annu Rev Clin Psychol. 2011;7:113-40.

51. Piantoni G, Romeijn N, Gomez-Herrero G, Van Der Werf YD, Van Someren EJW. Alpha Power Predicts Persistence of Bistable Perception. Sci Rep. 2017 Jul 12;7(1):5208.

52. Barabási A-L. Scale-Free Networks: A Decade and Beyond. Science. 2009 Jul 24;325(5939):412-3.

53. Collerton D, Perry E, McKeith I. Why people see things that are not there: a novel Perception and Attention Deficit model for recurrent complex visual hallucinations. Behav Brain Sci. 2005 Dec;28(6):737-57; discussion 757-794.

54. O’Callaghan C, Hall JM, Tomassini A, Muller AJ, Walpola IC, Moustafa AA, et al. Visual Hallucinations Are Characterized by Impaired Sensory Evidence Accumulation: Insights From Hierarchical Drift Diffusion Modeling in Parkinson's Disease. Biol Psychiatry Cogn Neurosci Neuroimaging. 2017 Nov 1;2(8):680-8.

55. Tranel D, Vianna E, Manzel K, Damasio H, Grabowski T. Neuroanatomical Correlates of the Benton Facial Recognition Test and Judgment of Line Orientation Test. J Clin Exp Neuropsychol. 2009 Feb;31(2):219-33. 
medRxiv preprint doi: https://doi.org/10.1101/2020.12.09.20246850; this version posted December 11, 2020. The copyright holder for this preprint (which was not certified by peer review) is the author/funder, who has granted medRxiv a license to display the preprint in perpetuity. It is made available under a CC-BY 4.0 International license .

56. Suzuki Y, Hirayama K, Shimomura T, Uchiyama M, Fujii H, Mori E, et al. Changes in pupil diameter are correlated with the occurrence of pareidolias in patients with dementia with Lewy bodies. Neuroreport. 2017 Mar 1;28(4):187-92.

57. Marathe AR, Ries AJ, McDowell K. Sliding HDCA: single-trial EEG classification to overcome and quantify temporal variability. IEEE Trans Neural Syst Rehabil Eng Publ IEEE Eng Med Biol Soc. 2014 Mar;22(2):201-11.

58. Armstrong RA. Visual symptoms in Parkinson's disease. Park Dis. 2011;2011:908306. 